\title{
A low-cost monitor for simultaneous measurement of fine particulate matter and aerosol optical depth - Part 1: Specifications and testing
}

\author{
Eric A. Wendt ${ }^{1}$, Casey W. Quinn ${ }^{2}$, Daniel D. Miller-Lionberg ${ }^{3}$, Jessica Tryner ${ }^{1}$, Christian L'Orange ${ }^{1}$, Bonne Ford ${ }^{4}$, \\ Azer P. Yalin ${ }^{1}$, Jeffrey R. Pierce ${ }^{4}$, Shantanu Jathar ${ }^{1}$, and John Volckens ${ }^{1,2}$ \\ ${ }^{1}$ Department of Mechanical Engineering, Colorado State University, Fort Collins, 80523, USA \\ ${ }^{2}$ Department of Environmental and Radiological Health Sciences, Colorado State University, Fort Collins, 80523, USA \\ ${ }^{3}$ Access Sensor Technologies LLC, Fort Collins, 80523, USA \\ ${ }^{4}$ Department of Atmospheric Science, Colorado State University, Fort Collins, 80523, USA
}

Correspondence: John Volckens (john.volckens@ colostate.edu)

Received: 19 March 2019 - Discussion started: 11 April 2019

Revised: 20 July 2019 - Accepted: 23 August 2019 - Published: 11 October 2019

\begin{abstract}
Globally, fine particulate matter $\left(\mathrm{PM}_{2.5}\right)$ air pollution is a leading contributor to death, disease, and environmental degradation. Satellite-based measurements of aerosol optical depth (AOD) are used to estimate $\mathrm{PM}_{2.5}$ concentrations across the world, but the relationship between satelliteestimated AOD and ground-level $\mathrm{PM}_{2.5}$ is uncertain. Sun photometers measure AOD from the Earth's surface and are often used to improve satellite data; however, referencegrade photometers and $\mathrm{PM}_{2.5}$ monitors are expensive and rarely co-located. This work presents the development and validation of the aerosol mass and optical depth (AMOD) sampler, an inexpensive and compact device that simultaneously measures $\mathrm{PM}_{2.5}$ mass and AOD. The AMOD utilizes a low-cost light-scattering sensor in combination with a gravimetric filter measurement to quantify ground-level $\mathrm{PM}_{2.5}$. Aerosol optical depth is measured using optically filtered photodiodes at four discrete wavelengths. Field validation studies revealed agreement within $10 \%$ for AOD values measured between co-located AMOD and AErosol RObotics NETwork (AERONET) monitors and for $\mathrm{PM}_{2.5}$ mass measured between co-located AMOD and EPA Federal Equivalent Method (FEM) monitors. These results demonstrate that the AMOD can quantify AOD and $\mathrm{PM}_{2.5}$ accurately at a fraction of the cost of existing reference monitors.
\end{abstract}

\section{Introduction}

Fine particulate matter air pollution $\left(\mathrm{PM}_{2.5}\right)$ is a leading contributor to premature death and disease globally (Brauer et al., 2016; Forouzanfar et al., 2016). When inhaled, $\mathrm{PM}_{2.5}$ can penetrate deep into the lungs, which can cause long- and short-term health problems (Nel, 2005; Pope and Dockery, 2006). In 2015, approximately 4.2 million premature deaths were attributed to ambient $\mathrm{PM}_{2.5}$ exposure (Forouzanfar et al., 2016).

Recently, satellite observations have been used to estimate $\mathrm{PM}_{2.5}$ levels at the Earth's surface. These estimates have facilitated global estimates of air pollution's impact on public health, especially in remote and resource-limited environments (Brauer et al., 2016). Satellite-based observations provide an estimate of aerosol optical depth (AOD), a dimensionless measure of light extinction in the atmospheric column. Satellite-derived AOD retrievals are then used to estimate $\mathrm{PM}_{2.5}$ concentrations at the Earth's surface (van Donkelaar et al., 2006, 2010; Lv et al., 2016). The relationships between $\mathrm{AOD}$ and $\mathrm{PM}_{2.5}$ concentration have been expressed as follows (Snider et al., 2015):

$\mathrm{PM}_{2.5}=\eta \cdot \mathrm{AOD}$,

where $\eta$ is a conversion factor between $\mathrm{PM}_{2.5}$ and AOD. If $\eta$ is known, satellite AOD estimates can be directly converted to surface $\mathrm{PM}_{2.5}$ concentrations. However, this conversion factor is sensitive to aerosol properties, aerosol com- 
position, surface reflectivity, and vertical profile, all of which can vary across time and space (van Donkelaar et al., 2006, 2010, 2013). Thus, satellite estimates of AOD are prone to error (Boersma and de Vroom, 2006; Brooks and Mims, 2001; Holben et al., 1998; Mims, 1999; Snider et al., 2015).

To improve satellite AOD retrievals, Sun photometers are routinely used to measure AOD from the Earth's surface (Levy et al., 2005). Sun photometers use photodetectors to measure the incident flux of photons at a given wavelength of light. In conjunction with the Beer-Lambert-Bouguer law, aerosol optical depth $\left(\tau_{\mathrm{a}}\right)$ may be calculated from a Sun photometer measurement per the following equation:

$\tau_{\mathrm{a}}(\lambda)=\frac{1}{m}\left(\ln \left(\frac{V_{0}}{R^{2}}\right)-\ln (V)\right)-\tau_{\mathrm{R}}(\lambda, p)-\tau_{\mathrm{O}_{3}}$,

where $m$ is the relative optical air mass factor, which accounts for different path lengths through the atmosphere when the Sun is at different angles, $R$ is the Earth-Sun distance in astronomical units (AU), $V$ is the voltage read by the light detector, $\tau_{\mathrm{R}}$ accounts for Rayleigh scattering by air molecules, $p$ is the pressure, $\lambda$ is the wavelength, $\tau_{\mathrm{O}_{3}}$ accounts for ozone absorption, and the extraterrestrial constant, $V_{0}$, is the voltage produced by incident light at the top of the atmosphere (Brooks and Mims, 2001; Boersma and de Vroom, 2006). $V_{0}$ must be evaluated via calibration. The primary method to find $V_{0}$ is the Langley plot method. By combining the aerosol, ozone absorption, and Rayleigh components into total optical depth $(\tau)$ and rearranging Eq. (2), the following equation (used for a Langley plot) is derived:

$\ln (V)=\ln \frac{V_{0}}{R^{2}}-\tau \cdot m$.

During a Langley calibration, voltage measurements are taken as the air mass factor changes over the course of a day. The slope of the line gives total optical depth and the intercept at $m=0$ gives the constant $V_{0}$. Secondary extraterrestrial constant calibrations may be performed relative to units calibrated via the Langley plot method (Boersma and de Vroom, 2006). Relative calibrations may be performed by taking coincident measurements with a calibrated and an uncalibrated unit and solving Eq. (2) for $V_{0}$, with $V$ equal to the light detector voltage from the uncalibrated unit, $\tau_{\mathrm{a}}$ equal to the AOD reported by the calibrated unit, and all other parameters equal to those reported by the uncalibrated unit.

When AOD is measured at multiple wavelengths, and the Ångström exponent, $\alpha$, is known, AOD for non-measured wavelengths may be inferred from the following relation (Ångström, 1929):

$\tau_{\mathrm{a}}(\lambda)=\tau_{\mathrm{a} 0} \cdot\left(\lambda_{0}\right) \cdot\left(\frac{\lambda}{\lambda_{0}}\right)^{-\alpha}$,

where $\lambda_{0}$ is a wavelength measured by the photometer, $\lambda$ is the new wavelength, and $\tau_{\mathrm{a} 0}$ is the measured AOD from the photometer. The Angström exponent varies depending on the aerosol size distribution; $\alpha$ tends to decrease with increasing particle size and may not be constant across all wavelength pairs (Eck et al., 1999; O'Neill, 2003). When AOD is measured at multiple wavelengths, curvature in $\alpha$ can be calculated, providing more insight into the aerosol properties (Eck et al., 1999).

Equation (2) assumes that the photometer measures the intensity of monochromatic light (Brooks and Mims, 2001). Because the Sun emits polychromatic light, Sun photometers feature light detectors with narrow spectral bandwidth (Shaw, 1983). Light detectors with full width at half maximum (FWHM) spectral bandwidths of $15 \mathrm{~nm}$ or narrower can be approximated as monochromatic, permitting the application of Eq. (2) with negligible error (Brooks and Mims, 2001). The requirement of approximately monochromatic detection precludes the use of photodiode sensors with broad spectral bandpass $(>30 \mathrm{~nm}$ ). CE318 (Cimel Electronique SAS, Paris, France) Sun photometers used in the AErosol RObotics NETwork (AERONET), a global reference network of Sun photometers, include photodiodes fitted with optical interference filters to achieve approximately monochromatic detection (Holben et al., 1998). However, high-quality bandpass filters can be cost prohibitive (e.g., USD > 100) (Holben et al., 1998; Mims, 1999). The high cost of the lightsensing elements partially contributes to the overall high cost (e.g., USD > 50 000) of Sun photometers used in AERONET. Previous studies have used light-emitting diodes (LEDs) acting as detectors as a low-cost alternative to optical interference filters (Boersma and de Vroom, 2006; Brooks and Mims, 2001; Mims III, 1992). Other studies have used relatively low-cost (USD < 30) integrated optical filter and photodiode modules (Murphy et al., 2016). The increasing availability of inexpensive alternatives has facilitated the production of relatively inexpensive Sun photometers, which are more cost-effective for large-scale deployments (Brooks and Mims, 2001).

$\mathrm{PM}_{2.5}$ samplers co-located with Sun photometers can help inform the relationship between AOD and surface $\mathrm{PM}_{2.5}$ concentration. The U.S. Environmental Protection Agency, which regulates ambient concentrations of $\mathrm{PM}_{2.5}$ mass (Noble et al., 2001), has designated a list of Federal Reference Methods (FRMs) and Federal Equivalent Methods (FEMs) that are used to monitor $\mathrm{PM}_{2.5}$ (US EPA, 2017) according to a set of design and performance characteristics (Noble et al., 2001). Like reference-grade Sun photometers, the deployment prospects of FRM and FEM monitors are limited by their cost (USD 10000-30000) and the need for line power.

The objective of this work was to develop a user-friendly and low-cost (relative to reference methods) aerosol sampler capable of accurate and precise AOD and $\mathrm{PM}_{2.5}$ measurements. We combined filtered-photodiode-based AOD measurements, time-resolved $\mathrm{PM}_{2.5}$ measurement via light scattering, and a time-integrated, gravimetric $\mathrm{PM}_{2.5}$ mass measurement to accomplish this objective. The resultant device, the aerosol mass and optical depth (AMOD) sampler, is capa- 


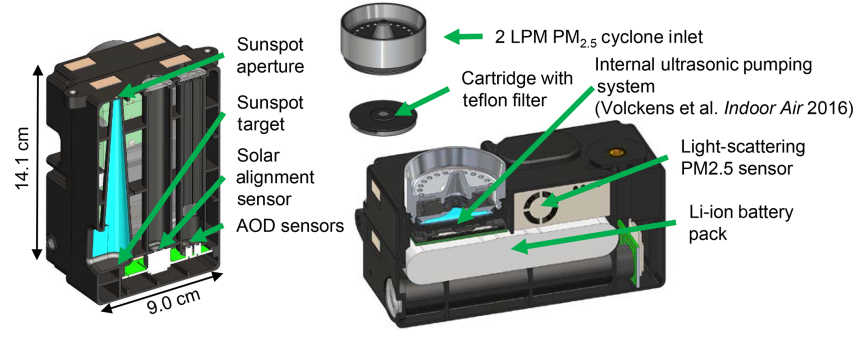

Figure 1. Computer-aided design rendering of key components of the AMOD including AOD and $\mathrm{PM}_{2.5}$ measurement systems, shown as cross-sectional cutaways.

ble of simultaneous Sun photometry and mass-based particulate matter measurements. In this work, we describe the design of the first-generation AMOD and its validation against reference monitors in real-world environments. We conclude this work by evaluating the shortcomings of this generation of the AMOD and specifying ongoing design improvements.

\section{Materials and methods}

\subsection{Instrument design}

The AMOD design was based on a low-cost gravimetric sampler known as the ultrasonic personal aerosol sampler (UPAS), which was developed through prior work (Volckens et al., 2017). The original, wearable UPAS housing was designed to measure personal exposure to aerosols in indoor and work environments (Volckens et al., 2017). Later, UPAS technology was integrated into a weatherproof housing for outdoor deployments to sample wildland fire smoke (Kelleher et al., 2018). The scientific goals of the AMOD development dictated the UPAS be modified for outdoor and primarily stationary measurement of both $\mathrm{PM}_{2.5}$ and AOD. Notable modifications included (a) additional hardware to support AOD measurement capability, (b) firmware updates for simultaneous $\mathrm{PM}_{2.5}$ and AOD sampling, (c) inclusion of a lowcost light-scattering sensor for real-time $\mathrm{PM}_{2.5}$ measurement, (d) a larger battery and a solar panel for extended battery life, and (e) a new weather-resistant housing. A computeraided rendering highlighting key internal and structural components of the AMOD is provided in Fig. 1.

The design of the AOD measurement system began with the selection of light sensors. Candidate sensors included filtered photodiodes (Murphy et al., 2016) (Intor Inc., Socorro, NM, USA), LEDs (Lighthouse LED A-FSMUBC12, WA, USA) (Mims III, 1992), and vertical cavity surface emitting lasers (VCSELs; Vixar Inc. I0-0680M-0000-KP01, Plymouth, MN, USA) - the last two operated as detectors. These sensor options were evaluated according to cost, variety of available center wavelengths, and spectral bandpass measured at full width at half maximum (FWHM). Spectral bandpass measurements were made using a tunable light source
(Optometrics TLS-25M, Littleton, MA, USA) for LED detectors and a tunable dye laser (Sirah Lasertechnik Allegro, Grevenbroich, Germany) for filtered photodiode and VCSEL detectors (Fig. S1 in the Supplement). Filtered photodiodes were selected for use in the AMOD due to their sufficiently narrow spectral response bandwidth $(<15 \mathrm{~nm})$ and relatively low cost. Filtered photodiodes were also commercially available at center wavelengths from 400 to $1000 \mathrm{~nm}$ in increments of approximately $10 \mathrm{~nm}$. No other detector option offered such a broad selection of wavelengths. LEDs were the least expensive option but were not selected due to their broad spectral response bandwidth. VCSELs were cost prohibitive and exhibited multiple undesirable response peaks (Fig. S1).

A printed circuit board containing AOD measurement instrumentation was designed using Autodesk $^{\circledR}$ EAGLE. When populated, this board contained four filtered photodiodes (Fig. S2), a quad operational amplifier with low leakage current (Linear Technology LTC 6242, Milpitas, California, USA), and a 16-bit analog-to-digital converter (Texas Instruments ADS1115, Dallas, Texas, USA). Photodiode wavelengths of $440,520,680$, and $870 \mathrm{~nm}$ were selected to avoid molecular absorption bands, to match wavelengths used by AERONET, and to facilitate aerosol size evaluation (O'Neill, 2003). A GPS (u-blox CAM-M8, Thalwil, Switzerland) provided location data (longitude, latitude, and altitude) needed to calculate the position of the Sun and estimate ozone optical depth. The board included circuitry for two optional components: (1) a solar incidence sensor (Solar MEMS NANOISS5, Seville, Spain) and (2) a Wi-Fi module (Espressif Systems ESP8266, Shanghai, China). The AOD measurement board was interfaced with the primary UPAS motherboard via I2C and UART communication. Sampler control firmware was written in $\mathrm{C}++$ on the mbed $^{\mathrm{TM}}$ platform (ARM ${ }^{\circledR}$ Ltd., Cambridge, UK).

A light-scattering particulate matter sensor (Plantower PMS5003, Beijing, China) was integrated into the sampler housing (Fig. 1). The PMS5003 included a fan that pulled aerosol through the path of a laser diode and a photodetector. Particulate matter concentrations were evaluated by a microprocessor embedded in the PMS5003 and accessed via serial communication (Zhou Yong, 2016). Performance of Plantower light-scattering sensors has been described previously (Bulot et al., 2019; Levy Zamora et al., 2019).

The AMOD housing was designed using SolidWorks ${ }^{\circledR}$ (ANSYS Inc., Canonsburg, PA, USA) and built using stereolithographic printing. The housing included four tubes that limited the field of view of the light detectors. Light entered through $5 \mathrm{~mm}$ diameter apertures on the top surface of the housing and subsequently passed through $112 \mathrm{~mm}$ long tubes to the active area of the filtered photodiodes. These dimensions yielded an angle of view of $2.56^{\circ}$ per sensor, approximately 5 times the angular diameter of the Sun, but within aperture ranges reported for other low-cost Sun photometers (Mims, 2002). A narrow viewing angle was required to miti- 


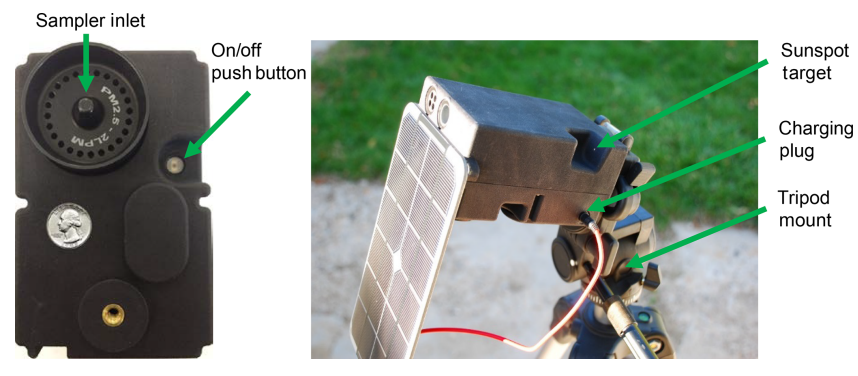

Figure 2. Photographs highlighting AMOD external hardware.

gate errors caused by forward-scattered sunlight entering the field of view of the detector (Torres et al., 2013). The housing also included a sealed inlet and outlet for flow through the PMS5003 sensor. Two sockets with 1/2-20 Unified National Coarse threads allowed the AMOD to be mounted to standard camera tripods. The housing was weather-resistant when mounted in its intended orientation, with the $\mathrm{PM}_{2.5}$ inlet facing the ground and the AOD apertures pointed toward the Sun (Fig. 2). An O-ring seal prevented leakage through the seam of the housing halves and float-glass windows sealed with foam adhesive protected the optical apertures.

The internal AMOD battery was a $3.6 \mathrm{~V}, 20.1$ Ah custom battery pack comprised of six 18650 lithium ion cells (Panasonic NCR18650B, Kadoma, Japan). The battery was charged via a barrel plug port on the side of the housing. This plug accepted power from a wall charger, external battery, or solar panel (Voltaic ${ }^{\circledR} 3.5 \mathrm{~W}$ ) and was watertight when the solar panel cable was attached to the barrel port. The removable solar panel was mounted to the exterior housing using magnets adhered to opposing surfaces on the panel and AMOD housing. Photographs of the external hardware in front and isometric orientations are provided in Fig. 2.

The dimensions of the AMOD were $9.0 \mathrm{~cm} \mathrm{~W} \times 14.1 \mathrm{~cm}$ $\mathrm{H} \times 6.7 \mathrm{~cm} \mathrm{~L}$ and the weight was $0.64 \mathrm{~kg}$. The total cost of goods of the AMOD was less than USD 1100 (Table S1 in the Supplement). This tabulation was based on a production run of 24 units. The average assembly time for a single AMOD was estimated at $2 \mathrm{~h}$, which translated to a cost of USD 50 at a rate of USD $25 \mathrm{~h}^{-1}$.

\subsection{Calibration procedure}

One AMOD master unit was calibrated relative to a Cimel CE318 at the DigitalGlobe AERONET site in Longmont, Colorado (Holben et al., 1998). AERONET instruments are calibrated using the Langley plot technique at Mauna Loa Observatory - or relative to other AERONET instruments that have been so calibrated - to AOD uncertainties between 0.002 and 0.005 (Eck et al., 1999). The master AMOD was calibrated relative to the Cimel CE318 by taking co-located and concurrent measurements over the course of 2 to $4 \mathrm{~h}$. The extraterrestrial constant $\left(V_{0}\right)$ was determined for each indi- vidual measurement by solving Eq. (2) using the AERONET value for AOD. The extraterrestrial constant for the master AMOD unit was then determined by averaging the extraterrestrial constant calculated from each individual measurement. The extraterrestrial constants of all other AMOD units were derived relative to the AMOD master unit by taking a series of simultaneous measurements under variable illumination (Boersma and de Vroom, 2006). The extraterrestrial constant for all other units, $V_{0, i}$, was determined as follows (Boersma and de Vroom, 2006):

$V_{0, i}=V_{0, \text { master }} \cdot \rho_{i}$,

where $V_{0, \text { master }}$ is the extraterrestrial constant of the master unit and $\rho_{i}$ is the average ratio of photodiode voltage readings from uncalibrated unit $i$ to the master unit. We recommend updating the calibration constants of AMOD instruments on a 6-month basis to account for changes in optical properties of the optical interference filters and photodiodes.

\subsection{AOD calculation algorithm}

We developed AOD calculation firmware using an online, open-source platform $\left(\right.$ mbed $^{\mathrm{TM}}$; $\mathrm{ARM}^{\circledR}$ Ltd., Cambridge, UK), which was executed by the onboard microcontroller (STMicroelectronics STM32L152RE, Geneva, Switzerland). Prior to applying Eq. (2) to calculate AOD, the Earth-Sun distance $(R)$, the relative optical air mass factor $(m)$, and the Rayleigh optical depth $\left(\tau_{\mathrm{R}}\right)$ were determined in accordance with the measurement location, time, pressure, and temperature. The National Renewable Energy Laboratory (NREL) published a solar position algorithm to calculate azimuth, elevation, and zenith angles at uncertainties equal to \pm 0.0003 as a function of location and time and for years between 2000 and 6000 (Reda et al., 2008). This algorithm was implemented as a $\mathrm{C}++$ microcontroller code to automate solar calculations for the AMOD. The Earth-Sun distance was calculated directly by the solar position algorithm.

The relative optical air mass factor was calculated in terms of the solar zenith angle, $\theta$, as follows (Young, 1994):

$m=\frac{1.002432 \cdot \cos ^{2}(\theta)+0.148386 \cdot \cos (\theta)+0.0096467}{\cos ^{3}(\theta)+0.149864 \cdot \cos ^{2}(\theta)+0.0102963 \cdot \cos (\theta)+0.000303978}$.

The contributions of Rayleigh scattering and ozone absorption to total optical depth are often substantial and must be subtracted from the total optical depth for accurate AOD measurements (Bodhaine et al., 1999). Rayleigh optical depth is inversely proportional to the fourth power of wavelength, which made accurate quantification especially important for the 440 and $520 \mathrm{~nm}$ channels on the AMOD. Rayleigh optical depth was calculated based on wavelength and ambient pressure measured by an onboard pressure sensor (Bosch Sensortec BMP280, Kusterdingen, Germany) (Bodhaine et al., 1999). The AMOD's 520 and $680 \mathrm{~nm}$ channels were within the Chappuis ozone absorption band (450$850 \mathrm{~nm})$. An empirical model was used to estimate ozone 
concentrations in Dobson units (DU) - based on the location and time of the measurement (Van Heuklon, 1979) - which were then used to determine the ozone optical depth (Koontz et al., 2013).

Finally, Eq. (2) was applied to determine the total optical depth using sensor inputs; the extraterrestrial constant; and the calculated Earth-Sun distance, relative optical air mass factor, Rayleigh optical depth, and ozone absorption optical depth. AOD, temperature, pressure, relative humidity, time, and location were then stored on an accessible microSD card (Molex 5031821852, Lisle, IL, USA).

\subsection{User operation and measurement procedure}

We designed the AMOD to be operated by individuals without a background in aerosol sampling but with an interest in air pollution and citizen science. Care was taken to minimize the complexity of the measurement process. A smartphone application guided the user through a single measurement in a series of steps (Fig. S3). Items needed to complete a measurement included an AMOD unit, a filter cartridge loaded with a pre-weighed air-sampling filter, a smartphone (iOS or Android enabled) with the device application ("CEAMS"; available in the Apple App Store and Google Play) downloaded, and a commercial tripod or alternative mount. Prior to initiating a measurement, the operator manually loaded the filter cartridge into position and aligned the AOD sensors with the Sun. The alignment process was aided by an integrated pinhole and target apparatus, which was geometrically aligned with the filtered photodiodes (Figs. 1,2). Once the AMOD was aligned, the operator initiated a sample with the smartphone application. The AMOD then recorded an instantaneous AOD measurement and began sampling air onto the filter under active control of the sample flow rate at $2 \mathrm{~L} \mathrm{~min}^{-1}$. The AMOD also began recording real-time $\mathrm{PM}_{2.5}$ levels reported by the PMS5003. Air sampling continued for $48.25 \mathrm{~h}$ before the AMOD automatically shut off. The AMOD maintained a fixed orientation on a tripod for the entire sampling duration - barring any unintended movements. The AMOD sampled AOD three times over the $48.25 \mathrm{~h}$ sampling period: immediately after the sample started, $24 \mathrm{~h}$ into the sample, and $48 \mathrm{~h}$ into the sample (i.e., at each solar overpass). To partially mitigate errors caused by day-to-day changes in the Sun's position, the AMOD began measuring AOD $15 \mathrm{~min}$ prior to the $24 \mathrm{~h}$ mark and logged AOD values every $30 \mathrm{~s}$ until $15 \mathrm{~min}$ after the $24 \mathrm{~h}$ mark. The operator was able to use this 30 min window to correct the AMOD's orientation if unintended movements had taken place since the start of the sample. The lowest AOD values, which corresponded with the highest photodiode signals, from the $30 \mathrm{~min}$ measurement window at 24 and $48 \mathrm{~h}$ were taken as the second and third AOD measurements. Upon completion of the sample, the operator downloaded data from the AMOD using the smartphone application and transferred the data to a host server.

\subsection{Co-location validation studies}

AMOD AOD measurements were validated in a series of colocation studies using AERONET CE318 monitors as the reference method (Holben et al., 1998). CE318 monitors used in the co-location studies had a $1.2^{\circ}$ full angle field of view and measured AOD at eight wavelengths: 340, 380, 440, 500, 675, 870, 1020, and $1640 \mathrm{~nm}$ (Holben et al., 1998). The CE318 monitors used stepping motors and closed-loop control to locate and track the Sun and reported measurements every 3-15 min when solar alignment was achieved (Holben et al., 1998). AERONET monitors were available at two sites along the Colorado Front Range: NEON-CVALLA (N $\left.40^{\circ} 09^{\prime} 39^{\prime \prime}, \mathrm{W} 105^{\circ} 10^{\prime} 01^{\prime \prime}\right)$ and Digital Globe (N $40^{\circ} 08^{\prime} 20^{\prime \prime}$, W $105^{\circ} 08^{\prime} 13^{\prime \prime}$ ). Device master calibrations were conducted at the Digital Globe site and device validation tests were conducted at NEON-CVALLA. Co-location tests took place on three separate days using seven different AMOD units: one calibrated directly relative to AERONET at the Digital Globe site and six calibrated via the transfer calibration method (Eq. 5). Between two and four calibrated AMOD units were randomly selected on each testing day and deployed within $50 \mathrm{~m}$ of the AERONET monitor. Four-wavelength AMOD AOD measurements were taken at $5 \mathrm{~min}$ intervals over the course of 1 to $4 \mathrm{~h}$ on each measurement day. AMOD data were then compared with Level 1.0 AOD data published in the online AERONET database (Holben et al., 1998). AMOD measurements concurrent within 2 min of an AERONET measurement were included in the comparison data set for the wavelength in question. The 500 and $675 \mathrm{~nm}$ AOD values from the AERONET instruments were adjusted - using Eq. (4) and Ångström coefficients from the AERONET data set - to match the 520 and $680 \mathrm{~nm}$ channels on the AMOD, respectively. The 440 and $870 \mathrm{~nm}$ channels required no adjustment because the AMOD and the AERONET monitors both measure at those wavelengths.

Time-integrated $\mathrm{PM}_{2.5}$ mass concentrations measured using the AMOD filter samples were validated in a series of $48 \mathrm{~h}$ co-location tests conducted with FEM monitors. AMOD units were loaded with $37 \mathrm{~mm}$ PTFE filters (MTL PT37P-PF03, Minneapolis, MN, USA). The FEM consisted of an EPA-certified louvered inlet $\left(\mathrm{PM}_{10}\right.$ - Mesa Labs SSI2.5, Lakewood, CO, USA) with an inline $\mathrm{PM}_{2.5} \mathrm{cy}$ clone (URG Corp 2161, Chapel Hill, NC, USA) operating at $16.7 \mathrm{~L} \mathrm{~min}^{-1}$. The $\mathrm{PM}_{2.5}$ sample was collected on a $47 \mathrm{~mm}$ PTFE filter (Tisch Scientific SF18040, North Bend, $\mathrm{OH}, \mathrm{USA})$. Airflow through the inlet, cyclone, and filter cartridge was maintained by a pump (Gast 86R142-P001BN270X, Benton Harbor, MI, USA) and metered using a mass-flow controller (Alicat MCRW-20SLPM-D/5M, Tucson, AZ, USA). Co-location tests occurred in multiple locations - including downtown Fort Collins, the Colorado State University main campus, and at several personal residences across the city - over a 10 -week period. We constructed a 
custom mount to support the FEM monitors and hold AMOD samplers at $40 \mathrm{~cm}$ from the FEM inlet (Fig. S4).

The $\mathrm{PM}_{2.5}$ mass concentrations measured using the PMS5003 included in the AMOD were evaluated against a co-located light-scattering FEM monitor (GRIMM EDM 180, Ainring, Germany) at the Colorado State University main campus (EPA monitoring site 08-069-0009). The GRIMM instrument utilized a $660 \mathrm{~nm}$ diode laser cell coupled with a light detector to measure particle concentrations based on light scattering. Flow through the GRIMM was maintained at $1.2 \mathrm{~L} \mathrm{~min}^{-1}$. $\mathrm{PM}_{2.5}$ readings from the AMOD PMS5003 were corrected post hoc, relative to the AMOD filter, by multiplying each light-scattering reading by a scaling factor equal to the ratio of the filter measurement to the $48 \mathrm{~h}$ average of the PMS5003. The PMS5003 outputs uncorrected $\mathrm{PM}_{2.5}$ concentrations as well as $\mathrm{PM}_{2.5}$ concentrations with a proprietary correction factor for use under atmospheric conditions. We used the corrected data output by the PMS5003 for our analyses. Hourly averages of the corrected readings were then calculated for comparison to the hourly concentrations reported by the GRIMM EDM 180.

\section{Results and discussion}

\subsection{AOD sensor evaluation}

Close agreement was observed between the AMOD and AERONET monitors for AOD. A comparison plot for all wavelengths and all AERONET co-location testing data is provided in Fig. 3 ( $n=130$ paired measurements for each wavelength). The mean absolute error between the AMOD and AERONET instruments was 0.0079 AOD units (across all wavelengths), yielding a mean relative error of $10 \%$. These deviations were nearly within the published uncertainties of the AERONET monitors (0.002-0.005) (Eck et al., 1999). The mean AOD difference was 0.00063 with $95 \%$ confidence upper and lower limits of agreement of 0.026 and -0.024 , respectively (Bland and Altman, 1986). A BlandAltman plot illustrating the mean difference and limits of agreement is provided in Fig. S5. The mean difference results indicated a low systematic bias between the two instruments in AOD units. The single set of outlier points shown in Fig. 3 was most indicative of a misalignment error because (1) the error relative to AERONET was at least $3 \times$ the error of all other measurements from the same AMOD unit; (2) measurements taken at the same time and location with different AMOD units exhibited lower error; and (3) the AOD was overpredicted by the AMOD, which is consistent with lower photodiode signal from misalignment. Agreement between AMOD units was comparable to the agreement between AMOD units and AERONET monitors. The average coefficient of variation between AMOD measurements, expressed as a percentage, was $9.0 \%$. We observed negligible performance differences between a master AMOD unit cali-

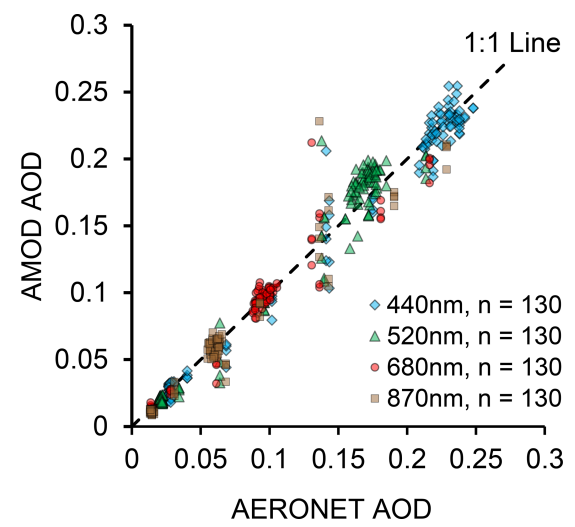

Figure 3. AERONET vs. AMOD AOD comparison plot. This plot includes all co-located measurements taken across all wavelengths between 3 September and 25 November 2017.

brated directly against AERONET instruments and those calibrated via transfer calibrations (Eq. 5). The average difference between units calibrated via the transfer calibration and the master unit was 0.006 AOD units.

Our evaluation was limited to relatively low AOD values due to the low aerosol concentrations at regional AERONET stations in fall 2017. We do not view this limitation as consequential because the linear dynamic range of the photodetectors used in the AMOD includes AOD values from 0 to 5 AOD units (specific voltages associated with AOD values are wavelength and calibration dependent). We plan to expand our performance evaluation to a broader range of environmental conditions in future work. Thin cirrus cloud cover on some days likely yielded the highest AOD values; while this was not strictly "aerosol" optical depth, it allowed for validation across a greater AOD range against the non-cloudfiltered Level 1.0 AERONET data.

Compared with AERONET monitors, the main advantages of the AMOD are its low cost and portability. The AMOD (including light-scattering and integrated $\mathrm{PM}_{2.5}$ monitoring) has a cost of goods $<40 \times$ lower than the purchase price of an AERONET CE318 monitor. The cost of goods - particularly circuit boards and mechanical components - would be reduced at higher quantities. Reference-grade CE318 monitors are advantageous with respect to measurement automation (e.g., Sun tracking allows for many measurements throughout the day), the number of AOD wavelengths (nine for the standard model), and the potential for additional sky radiation measurements beyond AOD (Holben et al., 1998).

AERONET co-location results indicate the AMOD can be used to measure AOD with high accuracy when measurements are initiated and overseen by an operator; however, it remains difficult to assess the reliability of unsupervised measurements taken at 24 and $48 \mathrm{~h}$ intervals after the original measurement. The proportions of the AOD apertures permit angular deviations from direct sunlight up to approximately $0.5^{\circ}$ for acceptable measurements. In Colorado, for exam- 
ple, the average day-to-day variation - for air mass values less than 5 - in the solar zenith and azimuth angles is $0.2^{\circ}$. Based on those day-to-day variations, the AMOD is most sensitive to alignment disturbances for measurements taken at the $48 \mathrm{~h}$ mark. An accelerometer reports the angular pitch of the AMOD relative to horizontal on a $30 \mathrm{~s}$ basis. We used those data to determine if the AMOD underwent large angular changes (e.g., $>2^{\circ}$ ) relative to the horizontal plane during sample collection. Wind and other disturbances can cause slight misalignment to occur between the first and second measurements that may not be detectable by the accelerometer. To help catch these events, a quadrant-photodiode-based solar-alignment sensor, mounted parallel to the AOD sensors, could be added to the AMOD to measure solar incidence angle for deviations smaller than $5^{\circ}$ at a precision of $0.1^{\circ}$. The sensor would measure solar alignment based on differential signals between elements of a quadrant photodiode array. Without automated self-correction or operator intervention, misalignment manifests itself with erroneously high AOD measures, which are similar to cloud-contaminated measurements. Manual screening requires operator attention, which cannot be expected for a $48+\mathrm{h}$ sampling period; however, erroneously high AOD measures, due to either misalignment or cloud contamination, can be identified and eliminated using an automated data screening algorithm.

The development of a low-cost solar tracking mount is also the subject of ongoing work. Active tracking would eliminate the need for algorithmic adjustments to account for daily solar position, enable measurement of daily AOD trends, increase solar power input, and enable robust cloud-screening algorithms. Closed-loop solar tracking will be facilitated by a quadrant diode solar-alignment sensor. Sensor-geometryspecific calibration factors enable accurate computation of two-dimensional incidence angles. Incidence angle information will be used in conjunction with a closed-loop motor control algorithm to locate and track the Sun.

AMOD measurements are amenable to reanalysis using ozone data from outside models or retrievals (Wargan et al., 2017). Reanalysis may be used to compensate for $\mathrm{NO}_{2}$ absorption in the 440 and $520 \mathrm{~nm}$ channels, which is unaccounted for in standard AMOD measurements. We plan to improve ozone compensation calculations as part of the second-generation AMOD design. Karavana-Papadimou et al. (2013) modified the model (Van Heuklon, 1979) parameters used in the AMOD algorithm using updated ozone measurements for select European cities (Karavana-Papadimou et al., 2013). The updated model achieved improved accuracy for European ozone predictions (Karavana-Papadimou et al., 2013). We plan to leverage ozone retrievals across the US to improve the model presently implemented by the AMOD. This approach can be extended into other regions as the need arises.

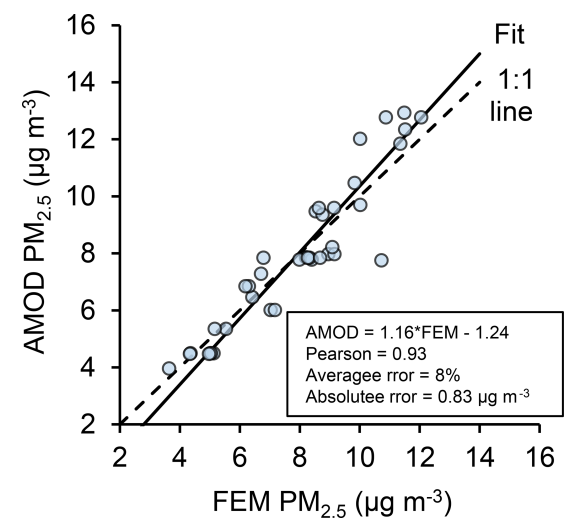

Figure 4. FEM $\mathrm{PM}_{2.5}$ measurements vs. AMOD $\mathrm{PM}_{2.5}$ measurements in micrograms per cubic meter $(n=39)$. Each data point represents a single $48 \mathrm{~h}$ time-weighted average. All fit statistics were evaluated via Deming regression, assuming equal variance contributions from both measurement devices.

\subsection{Gravimetric $\mathbf{P M}_{2.5}$ sampler evaluation}

Relatively good agreement was found between AMOD gravimetric $\mathrm{PM}_{2.5}$ and FEM samplers in the co-location study (see Fig. 4). The Pearson correlation between 39 colocated AMOD and FEM measurements was 0.93. The mean absolute error was $0.83 \mu \mathrm{g} \mathrm{m}^{-3}$, corresponding to a mean relative error of $8 \%$ between instruments. The mean difference was $-0.0037 \mu \mathrm{g} \mathrm{m}^{-3}$ with $95 \%$ confidence upper and lower limits of agreement of 1.84 and $-1.85 \mu \mathrm{g} \mathrm{m}^{-3}$, respectively (Bland and Altman, 1986). A Bland-Altman plot indicated a low systematic bias between the two instruments as a function of $\mathrm{PM}_{2.5}$ concentration (Fig. S6). These results were consistent with the agreement observed in previous work between $\mathrm{PM}_{2.5}$ mass concentrations measured using UPAS gravimetric samples and other accepted gravimetric sampling techniques (Arku et al., 2018; Kelleher et al., 2018; Pillarisetti et al., 2019; Volckens et al., 2017). These results are encouraging given the low $48 \mathrm{~h}$ average $\mathrm{PM}_{2.5}$ concentrations in Fort Collins during this period (ranging from 3.9 to $12.4 \mu \mathrm{g} \mathrm{m}^{-3}$ ).

Agreement between AMOD units was comparable to the agreement between AMOD units and FEM monitors. The average coefficient of variation between AMOD measurements taken concurrently with different units, expressed as a percentage, was $6.8 \%$. The relative standard deviation for AMOD gravimetric $\mathrm{PM}_{2.5}$ measurements collected using duplicate samplers at the same location was $4.9 \%$.

The performance of the AMOD $\mathrm{PM}_{2.5}$ sampler was promising in the context of its low cost and compact, portable form factor relative to the FEM. The AMOD cost of goods was less than the purchase price of the FEM used in the colocation studies by a factor of 12 . The AMOD was $97 \%$ lighter and more compact than the FEM when both were in their stowed configuration. Size comparisons when de- 
ployed depend on the apparatus used to mount the AMOD (e.g., camera tripod). The evaluation summarized in Fig. 4 was limited to relatively clean conditions in Colorado. In previous works, we have evaluated cyclone performance at concentrations from 15 to $40 \mu \mathrm{g} \mathrm{m}^{-3}$ and observed similar agreement with FEM monitors (Kelleher et al., 2018). Further, the UPAS technology (the gravimetric sampling technology with which the AMOD was developed) has been evaluated against reference monitors at concentrations approaching $1000 \mu \mathrm{g} \mathrm{m}^{-3}$ and in over 10 different countries with similar results (Arku et al., 2018; Pillarisetti et al., 2019).

\subsection{Light-scattering $\mathbf{P M}_{2.5}$ sensor evaluation}

Preliminary co-location results for the AMOD lightscattering sensor indicated relatively good agreement with a GRIMM FEM light-scattering sensor, albeit with an apparent directional bias. A box plot of paired average vs. paired difference $\mathrm{PM}_{2.5}$ concentration is provided in Fig. 5. Measurement pairs consist of temporally and spatially coincident, hourly average AMOD and FEM PM $\mathrm{P}_{2.5}$ measurements. Reported AMOD measurements are filter-corrected. Concentrations reported by the FEM ranged from 0 to $17 \mu \mathrm{g} \mathrm{m}^{-3}$. After normalizing the time-resolved AMOD measurements to the filter, the mean absolute error was $1.98 \mathrm{\mu g} \mathrm{m}^{-3}$. The mean difference was $0.04 \mu \mathrm{g} \mathrm{m}^{-3}$ with $95 \%$ confidence upper and lower limits of agreement of 5.02 and $-4.95 \mu \mathrm{g} \mathrm{m}^{-3}$, respectively (Bland and Altman, 1986). For pair-averaged $\mathrm{PM}_{2.5}$ concentrations less than $10 \mu \mathrm{g} \mathrm{m}^{-3}$, AMOD measurements were generally low relative to FEM measurements. For pair-averaged $\mathrm{PM}_{2.5}$ concentrations greater than $10 \mu \mathrm{g} \mathrm{m}^{-3}$, AMOD measurements were generally high relative to FEM measurements. This trend held for both corrected and uncorrected AMOD light-scattering sensor measurements (Fig. S7).

One limitation associated with the FEM and the PMS5003 is the low digital resolution. Both monitors report integer values (PMS5003 before filter normalization), which can magnify or obscure relative errors at low concentrations. Readings of $0 \mu \mathrm{g} \mathrm{m}^{-3}$ are especially problematic because they cannot be corrected to the filter via scaling factor multiplication. This leaves zero readings uncorrected and tends to magnify the scaling of nonzero readings (Fig. 5).

The AMOD light-scattering sensor represents cost savings over reference-quality light-scattering monitors and performance improvements over other low-cost sensors. The cost of goods of the AMOD is $20 \times$ less than the purchase prices of two reference quality monitors: the Thermo Fisher tapered element oscillating microbalance $\left(\mathrm{TEOM}^{\mathrm{TM}}\right)$ and the GRIMM monitor used in the co-location studies. Filter correction and weatherproof hardware integration may increase the accuracy and durability of the AMOD light-scattering measurement system compared with stand-alone low-cost sensors.

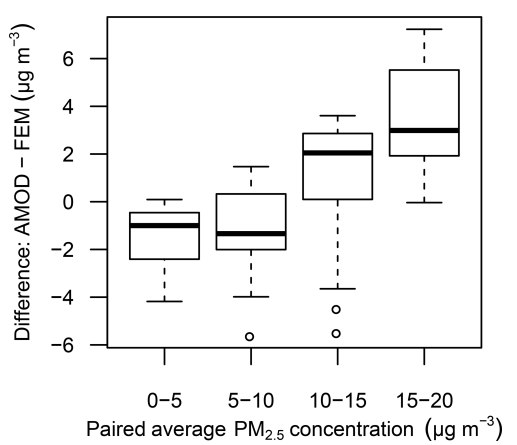

Figure 5. Binned paired average $\mathrm{PM}_{2.5}$ concentration vs. paired difference AMOD and FEM PM 2.5 measurements. Measurement pairs $(n=96)$ consist of AMOD and FEM measurements that are temporally and spatially coincident. The four size bins (upper bound inclusive) are $0-5 \mu \mathrm{g} \mathrm{m}^{-3}(n=30), 5-10 \mu \mathrm{g} \mathrm{m}^{-3}(n=$ $24), 10-15 \mu \mathrm{g} \mathrm{m}^{-3}(n=30)$, and $15-20 \mu \mathrm{g} \mathrm{m}^{-3}(n=12)$. All lightscattering AMOD measurements include the proprietary PMS5003 atmospheric correction and are further corrected to the corresponding AMOD filter measurement.

\subsection{Wireless capability}

Smartphone connectivity and control is an advantage of the AMOD. The custom AMOD smartphone application serves as a wireless control platform, condensed user manual, and data transfer tool. Wireless control allows the user to start the sampler without the risk of altering an established alignment. Systematic instructions reduce the potential for operator error and omission. Wireless data transfer is less labor intensive than hardware alternatives (e.g., $\mathrm{SD}^{\mathrm{TM}}$ card) and can be directly interfaced with a web server via the smartphone $\mathrm{Wi}$ Fi. The present Bluetooth ${ }^{\mathrm{TM}}$ smartphone application cannot connect to the AMOD while running, cannot display run data in the app, and downloads data at slow speeds (often in excess of 5 min for a full $48.25 \mathrm{~h}$ data set). Expanding the web connectivity of the AMOD to include real-time data transfer and visualization using the Wi-Fi chip is the subject of ongoing work. Basic data transfer and real-time visualization capabilities have been developed for the AMOD using a free Internet of Things (IoT) service (ThingSpeak ${ }^{\mathrm{TM}}$ ) and the ESP8266 Wi-Fi chip. Further development could enable faster data transfer and immediate feedback for participants in AMOD deployments. These capabilities could bolster the scientific potential of AMOD data, provide an interface with other web-connected devices, and facilitate operator engagement.

\subsection{Potential sampler network}

The unique combination of AOD, gravimetric filter $\mathrm{PM}_{2.5}$, and real-time $\mathrm{PM}_{2.5}$ sampling on a compact, user-friendly, and relatively low-cost platform makes the AMOD amenable to large-scale deployment in spatially dense sampling networks. Given these characteristics, the AMOD can be de- 
ployed in large numbers, by either trained or citizen scientists, to collect spatially dense AOD and $\mathrm{PM}_{2.5}$ data sets. These data sets, which can be used to gain a better understanding of spatial and temporal variations in the relationship between AOD and $\mathrm{PM}_{2.5}$ concentration, have the potential to improve and expand the use of satellite AOD-derived estimates of ground-level $\mathrm{PM}_{2.5}$ concentrations.

\section{Conclusions}

The AMOD is a lightweight and compact alternative to the instruments typically used to sample AOD and $\mathrm{PM}_{2.5}$. The AMOD represents a substantial cost savings compared with alternative $\mathrm{AOD}$ and $\mathrm{PM}_{2.5}$ mass concentration sampling equipment. In field testing, the AMOD exhibits agreement within $10 \%$ when compared with $\mathrm{AOD}$ and $\mathrm{PM}_{2.5}$ reference instruments. The AMOD has been validated only in a relatively clean air in Colorado in fall and wintertime; more validation in other environments of varying pollution and weather patterns is needed. The small size, durability, increased sampling capabilities, and relatively low cost of the AMOD make it a viable option for large-scale and spatially dense deployments. Such data sets have the potential to facilitate the calibration and validation of satellite-based sensors as they progress toward higher-spatial-resolution measurement capabilities.

Data availability. All AMOD data collected and used in this study are available at the following URL: https://doi.org/10.25675/10217/198162 (Wendt et al., 2019).

Supplement. The supplement related to this article is available online at: https://doi.org/10.5194/amt-12-5431-2019-supplement.

Author contributions. JV, JRP, SJ, and BF designed the study and concept for which the AMOD was designed. EW, CQ, DML, JT, $\mathrm{CL}, \mathrm{AY}$, and JV designed the AMOD device. EW, DML, and JT manufactured prototypes. EW, JT, CL, and AY designed and performed validation experiments. CQ designed the mobile application. EW led the paper with BF, JRP, SJ, and JV; and all co-authors contributed to interpretation of results and paper editing.

Competing interests. The authors declare that they have no conflict of interest.

Acknowledgements. The authors wish to thank John Mehaffy, Scott Kelleher, David Brooks, Marilee Long, Lizette van Zyl, Todd Hochwitz (Zebulon Solutions LLC, Longmont, CO, USA), Josh Smith, and Caroline Wendt for their contributions to this work. The authors also thank Michele Kuester of Digital Globe and Janae Csavina of NEON for their help securing AERONET colocation sites.

Financial support. This research has been supported by the NASA (grant nos. NNX17AF94A and 80NSSC18M0120).

Review statement. This paper was edited by Francis Pope and reviewed by two anonymous referees.

\section{References}

Ångström, A.: On the Atmospheric Transmission of Sun Radiation and on Dust in the Air, Geogr. Ann., 11, 156-166, https://doi.org/10.2307/519399, 1929.

Arku, R. E., Birch, A., Shupler, M., Yusuf, S., Hystad, P., and Brauer, M.: Characterizing exposure to household air pollution within the Prospective Urban Rural Epidemiology (PURE) study, Environ. Int., 114, 307-317, https://doi.org/10.1016/j.envint.2018.02.033, 2018.

Bland, M. J. and Altman, D.: Statistical Methods for Assessing Agreement Between Two Methods of Clinical Measurement, Lancet, 327, 307-310, https://doi.org/10.1016/S01406736(86)90837-8, 1986.

Bodhaine, B. A., Wood, N. B., Dutton, E. G., and Slusser, J. R.: On Rayleigh optical depth calculations, J. Atmos. Ocean. Tech., 16, 1854-1861, https://doi.org/10.1175/15200426(1999)016<1854:ORODC >2.0.CO;2, 1999.

Boersma, K. F. and de Vroom, J. P.: Validation of MODIS aerosol observations over the Netherlands with GLOBE student measurements, J. Geophys. Res.-Atmos., 111, 1-14, https://doi.org/10.1029/2006JD007172, 2006.

Brauer, M., Freedman, G., Frostad, J., van Donkelaar, A., Martin, R. V., Dentener, F., Dingenen, R. van, Estep, K., Amini, H., Apte, J. S., Balakrishnan, K., Barregard, L., Broday, D., Feigin, V., Ghosh, S., Hopke, P. K., Knibbs, L. D., Kokubo, Y., Liu, Y., Ma, S., Morawska, L., Sangrador, J. L. T., Shaddick, G., Anderson, H. R., Vos, T., Forouzanfar, M. H., Burnett, R. T., and Cohen, A.: Ambient Air Pollution Exposure Estimation for the Global Burden of Disease 2013, Environ. Sci. Technol., 50, 79_ 88, https://doi.org/10.1021/acs.est.5b03709, 2016.

Brooks, D. R. and Mims III, F. M.: Development of an inexpensive handheld LED-based Sun photometer for the GLOBE program, J. Geophys. Res., 106, 4733-4740, https://doi.org/10.1029/2000JD900545, 2001.

Bulot, F. M. J., Johnston, S. J., Basford, P. J., Easton, N. H. C., Apetroaie-cristea, M., Foster, G. L., Morris, A. K. R., and Cox, S. J.: Long-term field comparison of multiple low-cost particulate matter sensors in an outdoor urban environment, Sci. Rep., 1-13, 7497, https://doi.org/10.1038/s41598-019-43716-3, 2019.

Eck, T. F., Holben, B. N., Reid, J. S., Dubovik, O., Smirnov, A., O'Neill, N. T., Slutsker, I., and Kinne, S.: Wavelength dependence of the optical depth of biomass burning, urban, and desert dust aerosols, J. Geophys. Res.-Atmos., 104, 31333 31349, https://doi.org/10.1029/1999JD900923, 1999.

Forouzanfar, M. H., Afshin, A., Alexander, L. T., Biryukov, S., Brauer, M., Cercy, K., Charlson, F. J., Cohen, A. J., Dandona, 
L., Estep, K., Ferrari, A. J., Frostad, J. J., Fullman, N., Godwin, W. W., Griswold, M., Hay, S. I., Kyu, H. H., Larson, H. J., Lim, S. S., Liu, P. Y., Lopez, A. D., Lozano, R., Marczak, L., Mokdad, A. H., Moradi-Lakeh, M., Naghavi, M., Reitsma, M. B., Roth, G. A., Sur, P. J., Vos, T., Wagner, J. A., Wang, H., Zhao, Y., Zhou, M., Barber, R. M., Bell, B., Blore, J. D., Casey, D. C., Coates, M. M., Cooperrider, K., Cornaby, L., Dicker, D., Erskine, H. E., Fleming, T., Foreman, K., Gakidou, E., Haagsma, J. A., Johnson, C. O., Kemmer, L., Ku, T., Leung, J., Masiye, F., Millear, A., Mirarefin, M., Misganaw, A., Mullany, E., Mumford, J. E., Ng, M., Olsen, H., Rao, P., Reinig, N., Roman, Y., Sandar, L., Santomauro, D. F., Slepak, E. L., Sorensen, R. J. D., Thomas, B. A., Vollset, S. E., Whiteford, H. A., Zipkin, B., Murray, C. J. L., Mock, C. N., Anderson, B. O., Futran, N. D., Anderson, H. R., Bhutta, Z. A., Nisar, M. I., Akseer, N., Krueger, H., Gotay, C. C., Kissoon, N., Kopec, J. A., Pourmalek, F., Burnett, R., Abajobir, A. A., Knibbs, L. D., Veerman, J. L., Lalloo, R., Scott, J. G., Alam, N. K. M., Gouda, H. N., Guo, Y., McGrath, J. J., Charlson, F. J., Jeemon, P., Dandona, R., Goenka, S., Kumar, G. A., Gething, P. W., et al.: Global, regional, and national comparative risk assessment of 79 behavioural, environmental and occupational, and metabolic risks or clusters of risks, 1990-2015: a systematic analysis for the Global Burden of Disease Study 2015, Lancet, 388, 1659-1724, https://doi.org/10.1016/S0140-6736(16)31679$8,2016$.

Holben, B. N., Eck, T. F., Slutsker, I., Tanré, D., Buis, J. P., Setzer, A., Vermote, E., Reagan, J. A., Kaufman, Y. J., Nakajima, T., Lavenu, F., Jankowiak, I., and Smirnov, A.: AERONET - A Federated Instrument Network and Data Archive for Aerosol Characterization, Remote Sens. Environ., 66, 1-16, https://doi.org/10.1016/S0034-4257(98)00031-5, 1998.

Karavana-Papadimou, K., Psiloglou, B. E., Lykoudis, S., and Kambezidis, H. D.: Model for estimating atmospheric ozone content over Europe for use in solar radiation algorithms, Global Nest J., 15, 152-162, 2013.

Kelleher, S., Quinn, C., Miller-Lionberg, D., and Volckens, J.: A low-cost particulate matter $\left(\mathrm{PM}_{2.5}\right)$ monitor for wildland fire smoke, Atmos. Meas. Tech., 11, 1087-1097, https://doi.org/10.5194/amt-11-1087-2018, 2018.

Koontz, A., Flynn, C., Hodges, G., Michalsky, J., and Barnard, J.: Aerosol Optical Depth Value-Added Product, US Dep. Energy, March, 32, 2013.

Levy, R. C., Remer, L. A., Martins, J. V., Kaufman, Y. J., Plana-Fattori, A., Redemann, J., and Wenny, B.: Evaluation of the MODIS Aerosol Retrievals over Ocean and Land during CLAMS, J. Atmos. Sci., 62, 974-992, https://doi.org/10.1175/JAS3391.1, 2005.

Levy Zamora, M., Xiong, F., Gentner, D., Kerkez, B., KohrmanGlaser, J., and Koehler, K.: Field and Laboratory Evaluations of the Low-Cost Plantower Particulate Matter Sensor, Environ. Sci. Technol., 53, 838-849, https://doi.org/10.1021/acs.est.8b05174, 2019.

Lv, B., Hu, Y., Chang, H. H., Russell, A. G., and Bai, Y.: Improving the Accuracy of Daily PM 2.5 Distributions Derived from the Fusion of Ground-Level Measurements with Aerosol Optical Depth Observations, a Case Study in North China, Environ. Sci. Technol., 50, 4752-4759, https://doi.org/10.1021/acs.est.5b05940, 2016.
Mims, F. M.: Educational affairs: An International HazeMonitoring Network for Students, B. Am. Meteorol. Soc., 80, 1421-1431, 1999.

Mims, F. M.: An inexpensive and stable LED Sun photometer for measuring the water vapor column over South Texas from 1990 to 2001, Geophys. Res. Lett., 29, 2-5, https://doi.org/10.1029/2002GL014776, 2002.

Mims III, F. M.: Sun photometer with light-emitting diodes as spectrally selective detectors, Appl. Optics, 31, 6965-6967, 1992.

Murphy, D. M., Telg, H., Eck, T. F., Rodriguez, J., Stalin, S. E., and Bates, T. S.: A miniature scanning sun photometer for vertical profiles and mobile platforms, Aerosol Sci. Technol., 50, 11-16, https://doi.org/10.1080/02786826.2015.1121200, 2016.

Nel, A.: Air Pollution - Related Illness: Effects of Particles, Science, 308, 804-806, https://doi.org/10.1126/science.1108752, 2005.

Noble, C. A., Vanderpool, R. W., Peters, T. M., Frank, F. M., Gemmill, D. B., and Wiener, R. W.: Federal Reference and Equivalent Methods for Measuring Fine Particulate Matter Federal Reference and Equivalent Methods for Measuring Fine Particulate Matter, Aerosol Sci. Technol., 34, 457-464, 2001.

O'Neill, N. T.: Spectral discrimination of coarse and fine mode optical depth, J. Geophys. Res., 108, 4559, https://doi.org/10.1029/2002JD002975, 2003.

Pillarisetti, A., Carter, E., Rajkumar, S., Young, B. N., BenkaCoker, M. L., Peel, J. L., Johnson, M., and Clark, M. L.: Measuring personal exposure to fine particulate matter (PM2.5) among rural Honduran women: A field evaluation of the Ultrasonic Personal Aerosol Sampler (UPAS), Environ. Int., 123, 50-53, https://doi.org/10.1016/j.envint.2018.11.014, 2019.

Pope, C. A. and Dockery, D. W.: Health effects of fine particulate air pollution: Lines that connect, J. Air Waste Manage., 56, 709742, https://doi.org/10.1080/10473289.2006.10464485, 2006.

Reda, I., Andreas, A., and Nrel, A. A.: Solar Position Algorithm for Solar Radiation Applications (Revised), Nrel/Tp-560-34302, January, 1-56, https://doi.org/10.1016/j.solener.2003.12.003, 2008.

Shaw, G. E.: Sun Photometry, B. Am. Meteorol. Soc., 64, 4-10, https://doi.org/10.1175/15200477(1983)064<0004:SP>2.0.CO;2, 1983.

Snider, G., Weagle, C. L., Martin, R. V., van Donkelaar, A., Conrad, K., Cunningham, D., Gordon, C., Zwicker, M., Akoshile, C., Artaxo, P., Anh, N. X., Brook, J., Dong, J., Garland, R. M., Greenwald, R., Griffith, D., He, K., Holben, B. N., Kahn, R., Koren, I., Lagrosas, N., Lestari, P., Ma, Z., Vanderlei Martins, J., Quel, E. J., Rudich, Y., Salam, A., Tripathi, S. N., Yu, C., Zhang, Q., Zhang, Y., Brauer, M., Cohen, A., Gibson, M. D., and Liu, Y.: SPARTAN: a global network to evaluate and enhance satellite-based estimates of ground-level particulate matter for global health applications, Atmos. Meas. Tech., 8, 505-521, https://doi.org/10.5194/amt-8-505-2015, 2015.

Torres, B., Toledano, C., Berjón, A., Fuertes, D., Molina, V., Gonzalez, R., Canini, M., Cachorro, V. E., Goloub, P., Podvin, T., Blarel, L., Dubovik, O., Bennouna, Y., and de Frutos, A. M.: Measurements on pointing error and field of view of Cimel318 Sun photometers in the scope of AERONET, Atmos. Meas. Tech., 6, 2207-2220, https://doi.org/10.5194/amt-6-2207-2013, 2013. 
US EPA: Air Monitoring Methods - Criteria Pollutants, available at: http://www.epa.gov/ttn/amtic/criteria.html, last access: 20 February 2017.

van Donkelaar, A., Martin, R. V., and Park, R. J.: Estimating ground-level PM2.5 using aerosol optical depth determined from satellite remote sensing, J. Geophys. Res.-Atmos., 111, 1-10, https://doi.org/10.1029/2005JD006996, 2006.

van Donkelaar, A., Martin, R. V., Brauer, M., Kahn, R., Levy, R., Verduzco, C., and Villeneuve, P. J.: Global estimates of ambient fine particulate matter concentrations from satellite-based aerosol optical depth: Development and application, Environ. Health Persp., 118, 847-855, https://doi.org/10.1289/ehp.0901623, 2010.

van Donkelaar, A., Martin, R. V., Spurr, R. J. D., Drury, E., Remer, L. A., Levy, R. C., and Wang, J.: Optimal estimation for global ground-level fine particulate matter concentrations, J. Geophys. Res.-Atmos., 118, 5621-5636, https://doi.org/10.1002/jgrd.50479, 2013.

Van Heuklon, T. K.: Estimating atmospheric ozone for solar radiation models, Sol. Energy, 22, 63-68, https://doi.org/10.1016/0038-092X(79)90060-4, 1979.
Volckens, J., Quinn, C., Leith, D., Mehaffy, J., Henry, C. S., and Miller-Lionberg, D.: Development and evaluation of an ultrasonic personal aerosol sampler, Indoor Air, 27, 409-416, https://doi.org/10.1111/ina.12318, 2017.

Wargan, K., Labow, G., Frith, S., Pawson, S., Livesey, N., and Partyka, G.: Evaluation of the ozone fields in NASA's MERRA-2 reanalysis, J. Climate, 30, 2961-2988, https://doi.org/10.1175/JCLI-D-16-0699.1, 2017.

Wendt, E. A., Quinn, C. W., Miller-Lionberg, D. D., L'Orange, C., Ford, B., Yalin, A. P., Pierce, J. R., Jathar, S., and Volckens, J.: Data set associated with A low-cost monitor for simultaneous measurement of fine particulate matter and aerosol optical depth - Part 1: Specifications and testing, https://doi.org/10.25675/10217/198162, 2019.

Young, A. T.: Air mass and refraction, Appl. Optics, 33, 1108, https://doi.org/10.1364/AO.33.001108, 1994.

Zhou Yong, W.: Digital universal particle concentration sensor PMS5003 series data manual, available at: http://www.aqmd.gov/docs/default-source/aq-spec/ resources-page/plantower-pms1003-manual_v2-5.pdf?sfvrsn=2 (last access: 17 November 2017), 2016. 